\title{
Screening by colonoscopy - Has the time arrived?
}

\author{
RICHARD H HUNT, FRCP, FRCP(EDIN), FRCPC
}

\begin{abstract}
Colorectal cancer mortality may be reduced by several screening strategies - mathematical modelling suggests that mortality may be reduced by one-third in patients over the age of 40 years who undergo annual fecal occult blood testing. Similar modelling suggests that either colonoscopy or barium enema may reduce mortality by up to $85 \%$. This paper reviews the evidence for different screening approaches for colorectal cancer, and identifies high risk groups in whom full colonoscopy has been studied. These studies include patients with first degree relatives with colorectal cancer, family cancer syndrome, prior breast, uterine or ovarian lesions, and follow-up for prior adenomatous polyps or cancer. The role of colonoscopy in the surveillance of patients with chronic total ulcerative colitis for dysplasia is also reviewed. The implications for patient management and possible clinical strategies are discussed. Can J Gastroenterol $1990 ; 4(9): 527-432$
\end{abstract}

Key Words: Colonoscopy, Colorectal cancer, Dysplasia, Screening, Ulcerative colitis

\section{Dépistage par côlonoscopie - Le moment est-il arrivé?}

RESUME: Plusieurs stratégies de dépistage permettent de réduire la mortalité pour cancer recto-colique - les modèles mathématiques suggèrent que la mortalité peut être diminuée d'un tiers chez les patients âgés de plus de 40 ans qui subissent annuellement des tests de dépistage du sang occulte dans les selles. Des modèles similaires suggèrent que la côlonoscopie ou le lavement baryté permet une réduction pouvant atteindre $85 \%$. Le présent article examine les diverses méthodes de dépistage du cancer recto-colique et définit les groupes à haut risque pour qui la côlonoscopie complète a été étudiée (patients dont un parent proche est porteur de cancer recto-colique, syndrome de cancer familial, antécédents de cancer du sein, de l'utérus ou des ovaires; suivi des patients ayant eu des antécédents de polypes adénomateux ou de cancer). La surveillance côlonoscopique à la recherche de dysplasie des cas de colite ulcéreuse chronique à forme pancolique est également examinée. Les implications de la prise en charge et les stratégies cliniques possibles sont également proposées.

Division of Gastroenterology, McMaster University Medical Centre, Hamilton, Ontario Correspondence and reprints: Dr Richard H Hunt, Room 4W8, McMaster Medical Centre, 1200 Main Street West, Hamilton, Ontario L8N 325. Fax (4I6) 521-5072
CREening FOR COLORECTAL neoplasia has been widely advocated for patients aged 40 to 50 years and older, using hemoccult testing and flexible sigmoidoscopy followed, where indicated, by double contrast barium enema or, more commonly, colonoscopy $(1,2)$. The overall mortality rate of colorectal cancer approaches $60 \%$, and the detection of early lesions results in a mortality rate of $20 \%$ or less; there have, therefore, been many advocates of screening strategies.

To answer the key question of whether colorectal cancer screening is justifiable, several factors must be considered. Is the incidence of sufficient magnitude to justify the resources expended? What is the potential benefit and how should this be evaluated? Are there particular groups that can be targeted as high risk? How sensitive and specific are available tests? Are effective diagnostic and therapeutic modalities available? Would screening tests have good patient and physician acceptance? Is the program cost effective?

\section{MODELS OF COST EFFECTIVENESS}

In a mathematical model, Eddy et al (3) calculated that an annual fecal occult blood test in people older than 40 years 


\begin{tabular}{l} 
TABLE I \\
Patients at high risk for colorectal \\
neoplasia: Candidates for screening \\
\hline Family history of \\
Colorectal polyp \\
Colorectal cancer \\
History of \\
Ulcerative colitis \\
Breast cancer \\
Endometrial cancer \\
Crohn's disease \\
Visceral irradiation \\
Uterosigmoidoscopy \\
Colorectal polyp \\
Colorectal cancer
\end{tabular}

might reduce mortality by one-third. Colonoscopy or barium enema might reduce mortality by $85 \%$ and, performed every three to five years, preserves 70 to $90 \%$ of the efficacy of annual screening. Commencing screening at age 50 reduced effectiveness by 5 to $10 \%$.

In an attempt to determine the most cost effective strategy for the work-up of a positive fecal occult blood test, Barry and colleagues (4) applied a decision analysis model examining seven strategies. Rigid or flexible sigmoidoscopy alone was insensitive but had a high cost effectiveness ratio. Air contrast barium enema alone had the lowest cost effectiveness ratio, while rigid sigmoidoscopy and barium enema had a lower cost effectiveness ratio than primary colonoscopy, which was improved depending upon assumptions about the costs and benefit of polypectomy.

A further study of the cost effectiveness of strategies for screening for colorectal cancer concluded that for average risk patients a positive fecal occult blood should be followed by a double contrast barium enema, but for high risk patients such a test should be followed by colonoscopy (5).

Screening programs have shown a shift towards diagnosis of tumours at an earlier stage, and some series have reported lower mortality rates (1). However, the strategies of screening with hemoccult and sigmoidoscopy have been critically reviewed and questioned $(6,7)$. Since the false-negative rate for hemoccult is about $20 \%(8)$ and compliance only about $30 \%(8)$ or even as low as $15 \%(9)$, the combination of poor compliance and low sensitivity make screening particularly inefficient.

Two recent reports from the US Preventive Science Task Force $(10,11)$ make it clear that proof of a reduction in mortality is absent and emphasizes the problems of flexible sigmoidoscopy.

Finally, the most conservative estimates of the annual cost of such a screening strategy exceeds US\$1.1 billion, despite no conclusive evidence regarding efficacy in mortality reduction.

\section{HIGH RISK GROUPS}

Several groups are considered to be at increased risk of colorectal cancer (Table 1).

The increased risk is particularly evident for patients with a positive family history especially for multiple benign or malignant tumours, primary adenoma and carcinoma of the large bowel, and early age of onset (12).

\section{RECENT SCREENING STUDIES}

A recent randomized controlled trial of fecal occult blood screening for colorectal cancer in average risk subjects from Nottingham, United Kingdom has clearly shown that cancers detected by screening are at a less advanced pathological stage, although in this ongoing study it is too early to show any effect on mortality (13).

Effectiveness has not been well studied, but in an uncontrolled study 26,000 mostly asymptomatic subjects underwent 47,091 rigid proctosigmoidoscopies which detected 58 cancers, $81 \%$ of which were Dukes' stages A or B, with a 15 year survival of $90 \%$ (14), while Gilbertsen (15) has shown a reduction in rectal cancer in patients regularly sigmoidoscoped and whose polyps were removed. However, few or no data are available for the application of sigmoidoscopy, which has been increasingly superceded by the flexible sigmoidoscope-most commonly the 60 $\mathrm{cm}$ scope. This instrument detects two to four times the number of lesions, especially in the rectosigmoid.

Letsou et al (16) compared the results of the fecal occult blood test with endoscopic examination: in 348 patients with negative fecal occult blood, $55 \%$ had colonoscopy and $44.5 \%$ flexible sigmoidoscopy. Adenomatous polyps were detected in $25.7 \%$, colorectal cancer in $2.6 \%$, and diverticular disease in $36.2 \%$. Of the 185 patients with positive fecal occult blood, $76.5 \%$ had colonoscopy and $23.4 \%$ flexible sigmoidoscopy; polyps were found in $39.0 \%$, colorectal cancer in $10.1 \%$, and diverticular disease in $43.0 \%$. Thus, fecal occult blood was negative in $59 \%$ of patients with polyps and $36 \%$ with colorectal cancer.

Full colonoscopy has been investigated in a number of studies of patients at high risk for colorectal cancer. In a study of 154 patients with one or two first degree relatives with colorectal cancer, 48 also had affected second and third degree relatives; 45 adenomas were found in 28 patients $(18 \%)$, not greater than expected in the general population, and the authors did not consider colonoscopy an appropriate initial step (17). The same authors also performed a prospective study in 544 asymptomatic subjects, each with a history of a colorectal index lesion six months to 33 years previously, ranging from adenoma in 402 patients to one or more carcinomas in 142 patients (18). In patients with a single adenoma the prevalence of lesions detected at colonoscopy was above the level reached by rigid sigmoidoscopy. The prevalence of neoplasms increased with age, male sex and black race, and the number and size of the index adenoma(s). In the 142 patients with cancer, the incidence of lesions was marginally related to age and white race. A subgroup of 133 patients with a single tubular adenoma (less than $1 \mathrm{~cm}$ in size and with no first degree relative with a history of colorectal cancer) had only $3 \%$ prevalence of advanced colonic neoplasms, not greater than the general population. A total of 411 subjects held more advanced index lesions, and the prevalence of advanced neoplasms ranged from 8 to $18 \%$. The authors concluded that for patients with only a single small tubular adenoma and no family history of colorectal cancer, follow-up guidelines should be modified.

Several other studies have reported 
the result of colonoscopies in first degree relatives of colorectal cancer patients. In 48 patients who were selfor physician-referred because of a family history of one or more first degree relatives with colorectal cancer, 12 $(25 \%)$ had at least one adenomatous polyp, but no cancers were detected (19). This increase in adenomas was more striking in men over age 50 $(46 \%)$. Other similar reports have identified lesions in 17 to $63 \%$ of patients, including large polyps and malignant lesions; more than $20 \%$ of lesions were proximal to the splenic flexure $(20,21)$. However, some of these studies included patients with previous histories, which may have influenced the results.

In a study of kindred with colorectal cancer family syndrome, 2.36 asymptomatic members of 22 families were offered screening, and 137 (58\%) accepted (22). One screening visit revealed a colonic neoplasm in 12 subjects ( $9 \%$ ), two with carcinoma (Dukes' stages $\mathrm{A}$ and $\mathrm{B}$ ) and 10 with adenomas. Two family members not screened developed Dukes' stage C tumours, and one died. Continued screening of 34 patierts showed metachronous tumours in $12(35 \%)$, with nine operable cancers and nine adenomas over three years. However, there was a high rate of advanced lesions other than colorectal cancers.

In patients with prior histories of breast, uterine or ovarian lesions, screening with fecal occult blood, flexible sigmoidoscopy and colonoscopy when appropriate was reported by Rozen et al (23). A total of 183 patients were compared with 252 age- and ethnically matched controls. Neoplastic lesions were 2.5 times more frequent in the study group, and for patients with a history of breast cancer the relative risk was 3.0. The authors conclude that screening is of value in this group, but that it should be integrated into a combined colon, breast and gynecological lesion follow-up.

Colonoscopy for routine follow-up has been studied by Barkin et al (24), who followed 452 patients resected for colorectal cancer. Eighty-six of 380 colon cancer patients had recurrent disease, as did 21 of 72 rectal cancer patients. Local recurrence was defined as tumour within $4.0 \mathrm{~cm}$ of the anastomosis, and was seen in 38 of 86 colon and 11 of 21 rectal cancer patients. Of the 49 recurrences, 15 were intraluminal, and six were initially detected by the follow-up endoscopy program. Metachronous lesions were found in six colon cancer patients. The authors advocate a routine follow-up endoscopy program. However, staging of tumour and outcome were not given, and it is not clear what contribution the endoscopic information made to management. The value of regular follow-up for patients with large bowel cancer has been questioned $(25,26)$, and Ballantyne (27) emphasized that substantially more effort and resources are directed towards follow-up than to identification of disease at an earlier curable stage. Of 500 patients with 1240 polyps reviewed at colonoscopy over 13 years, $93 \%$ have been followed for an average of 53 months (28). Recurrent polyps occurred in $26 \%$ with approximately $7 \%$ malignant; this compares to a metachronous cancer rate of $7 \%$ in patients with previous malignancies $(26,29)$. The highest risk of recurrence was in patients with more than four polyps at initial colonoscopy.

It is reasonable, therefore, to conclude that it would be premature to consider colonoscopy appropriate for primary screening in subjects considered at average risk for colorectal cancer. Furthermore, colonoscopy in subjects who have a first degree relative with colon cancer, or who have prior breast or gynecological cancer, has a relatively low yield. For subjects having two or more first degree relatives affected with colorectal cancer, colonoscopy may be justified.

Colonoscopy in the follow-up of patients with prior colorectal cancer is also disappointing, with most recurrences occurring outside the bowel lumen. However, for those with a prior Dukes' stage $\mathrm{A}$ or $\mathrm{B}$ lesion and for young patients with a Dukes' stage C lesion, follow-up colonoscopy to detect metachronous lesions is appropriate initially on an annual basis, decreasing in frequency over time. Colonoscopic follow-up for patients with adenomatous polyps is more contentious - those with a single small tubular adenoma probab. ly only require examination every three to five years, while those with multiple and/or large adenomas with or without dysplasia will require more frequent $\mathrm{ex}$ amination every two to four years after two initial annual colonoscopies to ensure that the colon is free from polyps.

\section{ULCERATIVE COLITIS}

The recognition of a premalignant abnormality which could be detected histologically (30) has made possible a screening program for patients with longstanding ulcerative colitis, although the frequency with which screening should be carried out is not yet clear, and there is as yet no evidence that such a program has significantly altered the course and outcome of the disease.

Currently, the pathological staging of patients with carcinoma is purely a matter of chance; some will be relatively early and fortunately cured, while a similar patient may have disseminated disease and die rapidly. The hope is that early detection of invasive carcinoma will result in an increased cure rate, and not just increased survival time which could be the result of lead time bias. To date, no trial has convincingly demonstrated the benefit of detection of dysplasia or presymptomatic carcinoma in a surveillance program to prevent deaths from carcinoma; however, such studies may never be carried out because of the potential difficulties in randomizing patients with any form of 'premalignancy' to the appropriate control arm of a randomized clinical trial.

\section{DYSPLASIA AS A PREMALIGNANT LESION}

The identification of a premalignant lesion can only be effective if at least the vast majority of invasive carcinomas either arise directly from, or are associated with such a lesion.

Dysplasia in ulcerative colitis can be defined as an unequivocally neoplastic proliferation essentially equivalent to an adenoma (31); it usually occurs against a background of longstanding inflammation. It excludes all equivocal 
TABLE 2

Schema of patient management related to classification of dysplasia

\begin{tabular}{l} 
Biopsy classification \\
\hline Negative \\
Normal mucosa \\
Inactive (quiescent) colitis \\
Active colitis \\
Indefinite \\
Probably negative \\
Unknown \\
Probably positive \\
Positive \\
Low grade dysplasia
\end{tabular}
Implications for patient management

Continue regular follow-up

Normal mucosa

Inactive (quiescent) colitis

e colitis

Probably negative

Unknown

Positive

Low grade dysplasic

Institute short interval follow-up or consider colectomy, especially with DALM, after dysplasia is confirmed

High grade dysplasia DALM Dysplasia-associated lesion or mass

Consider colectomy after dysplasia is confirmed

or regenerative lesions, and may be the superficial part of an invasive carcinoma. In addition, areas of dysplasia may be visible to the endoscopist (32). Biopsies taken to assess the presence of dysplasia can be categorized as negative, indefinite or positive for dysplasia (31). Re-biopsy over several months and on several occasions may be necessary for doubtful lesions and to ensure that adjacent areas of unequivocal dysplasia are not also present.

Macroscopic appearance: At endoscopy, arews of dysplasia may be seen as raised above the adjacent mucosa and appear as plaques or irregular areas of nodularity. The latter are often poorly circumscribed, in marked contrast to adenomas, which are invariably well circumscribed and may be pedunculated, broad-based or sessile.

These differences in appearance have three distinct clinical implications. First, when surveillance is used to detect dysplasia, the possible gross appearances of the lesion being sought must be borne in mind and deliberately looked for.

Second, any form of dysplasia has the potential for giving rise to or being the superficial part of an invasive carcinoma.

Third, the question of whether adenomas can exist or coexist in situations where dysplasia is encountered needs to be considered. In ulcerative colitis, lesions indistinguishable from adenomas by all criteria appear to be relatively common, and endoscopic excision appears safe and unassociated with an excess of carcinoma either in the lesion itself or in the remainder of the colon.

A major factor involving dysplasia and adenoma is the concept of the dysplasia-associated lesion or mass (DALM) (32). If the clinician is unfamiliar with the DALM concept, the lesion may be treated as an adenoma. However, if the pathologist makes a diagnosis of dysplasia, then the clinician must immediately consider whether colectomy is the appropriate management.

Implications for patient management: If the policy is to follow low grade dysplasia, it should be recognized that one is deliberately following a lesion which can give direct rise to invasive carcinoma which may already have developed. Furthermore, these carcinomas may not always be readily recognized clinically in patients with inflammatory bowel disease.

Endoscopy and diagnosis of dysplasia: Proctosigmoidoscopy provides a limited view localized to the rectum, and the opportunity to obtain rectal biopsies. Rectal biopsies have been widely advocated for following patients with chronic ulcerative colitis $(33,34)$, but more recent studies have suggested that as many as $75 \%$ of patients with colonic dysplasia do not have rectal involvement. Colonoscopy provides the optimal examination of the colon, and the opportunity for multiple biopsies for a representative sampling from the whole colon. All suspicious areas should be biopsied, especially areas of mucosal irregularity, eg, where the surface appears 'velvety', and any mass lesion, as dysplasia associated with such a lesion increases significantly the probability of carcinoma $(32,35)$.

Inflammatory polyps should be biopsied when they are larger than $1 \mathrm{~cm}$ in diameter, have an irregular friable surface, or are different in colour or appearance from surrounding polyps.

Although strictures in chronic colitis are less often malignant than originally thought (36), multiple biopsies should be obtained. Malignancy should be suspected if the lesion has a shelflike margin, is unyielding to the colonoscope, or is friable and hemorrhagic.

\section{CLINICAL STRATEGIES FOR EARLY DETECTION}

Follow-up strategies fall into one of four categories: do nothing, regular follow-up and biopsy, follow-up and biopsy at short intervals, and excision of the diseased organ.

The biopsy classification determined by an international working party can be used to guide patient management (Table 2). When the biopsy classification is negative or indefinite (probably negative), the patient should continue with regular, annual follow-up; when the interpretation is unclear but probably positive, a short interval follow-up of three to six months should be instituted; and when low grade dysplasia is confirmed, three monthly follow-up must be undertaken and colectomy considered if a DALM is present. When high grade dysplasia is reported, colectomy should be undertaken, although some would advocate confirmation of high grade dysplasia before indicating surgery.

Doing nothing can be advocated in patients in whom further surgery would not be contemplated even if something was found. Regular follow-up is carried out in patients without evidence of dysplasia.

\section{COLONOSCOPIC SURVEILLANCE STUDIES}

Colonoscopic surveillance has been reported in at least 12 series involving over 1200 patients with ulcerative colitis $(32,34,37-46)$. Random biopsies revealed dysplasia in about $20 \%$ of 
patients and carcinoma in about $0.6 \%$, although this rose to $3.6 \%$ in surgical specimens. In patients in whom dysplasia is detected, 15 to $18 \%$ will ultimately have carcinoma, while about $10 \%$ of patients with cancer have no evidence of dysplasia in any of their colonoscopic biopsies.

It is not possible from current data to make firm recommendations as to intervals of follow-up. An interval of two to three years may be too long because carcinoma could develop or progress to an intractable stage between examinations, and colonoscopy may not have provided a complete view of the colon. A strategy of two-yearly follow-up can certainly miss lesions (47), but there is no evidence that a program of annual follow-up will not also miss lesions.

Failures occur in any surveillance program, including endoscopic errors of perception and an inadequate number of biopsies, considering the known focality of dysplasia and even carcinoma in colitis. The current practice is to take one or two biopsies every 10 $\mathrm{cm}$ throughout the colon. Assuming that the circumference of the colon is $10 \mathrm{~cm}$, this approach would sample 5 to $10 \mathrm{~mm}^{2}$ from each $100 \mathrm{~cm}^{2}$ of colon (ie, $1 / 20,000$ to $1 / 10,000$ ) (48). An increase in the number of biopsies from each

\section{REFERENCES}

1. Winawer S]. Screening for colorectal cancer. In: DeVita VT, Hellman S, Rosenberg SA, eds. Cancer Principles and Practice of Oncology, Vol 1. Philadelphia: JB Lippincott Co, 1987:1-16.

2. Fleischer DE, Goldberg SB, Browning $\mathrm{TH}$. Detection and surveillance of colorectal cancer. JAMA 1989;261:580-5.

3. Eddy DM, Nugent FW, Eddy JF, et al. Screening for colorectal cancer in a high-risk population - Results of a mathematic model. Gastroenterology 1987;92:682-92.

4. Barry MJ, Mulley AG, Richter JM. Effect of workup strategy on the costeffectiveness of fecal occult blood screening for colorectal cancer. Gastroenterology 1987;93:301-10

5. England WL, Halls JJ, Hunt VB. Strategies for screening for colorectal carcinoma. Med Decision Making 1989;9:3-13.

6. Simon JB. Occult blood screening for segment of colon at each surveillance examination is one approach to decrease sampling error. A further reason for failure is histopathological interpretation; however, acceptance of the international classification will help reduce this source of failure (31).

A more pragmatic approach might be to defer intervals to two or three years if the initial three annual examinations do not show any evidence of dysplasia. Flexible sigmoidoscopy might be considered in the intervening years.

\section{CONCERN OVER RECOMMENDATIONS}

A number of important questions are raised by the implementation of a surveillance program. First, does it detect all cases with dysplasia and all cases with invasive cancer? If not, how many patients are missed? Second, what proportion of invasive cancers are detected de novo without detection of prior dysplasia? Third, what is the prognosis of established cancer diagnosed in a surveillance program, and do conventional survival criteria apply?

The policy of colonoscopic surveillance for chronic total ulcerative colitis has been questioned by Collins et al (49), who concluded that: the premises

colorectal carcinoma: A critical review. Gastroenterology 1985;88:820-37.

7. Clayman CB. Mass screening for colorectal cancer: Are we ready? JAMA 1989;261:609.

8. Farrands PA, Britton DC. Intervention in large bowel carcinogenesis - Does screening improve prognosis? Scand J Gastroenterol 1984;5(Suppl 104):151-9.

9. Elwood TW, Erickson A, Lieberman S. Comparative educational approaches to screening for colorectal cancer. Am J Public Health 1978;68:135-8.

10. Knight KK, Fielding JE, Battista RN. Occult blood screening for colorectal cancer. JAMA 1989;261:586-93.

11. Selvy JV, Friedman GD. Sigmoidoscopy in the periodic health examination of asymptomatic adults. JAMA 1988;261:594-601.

12. Lovett E. Family studies in cancer of the colon and rectum. $\mathrm{Br} \mathrm{J}$ Surg 1976;63:13-8.

13. Hardcastle JD, Chamberlain J, for surveillance are not well established; there is no compelling evidence that surveillance is beneficial; a surveillance program cannot guarantee that a lethal cancer will not develop; and even if some patients do benefit it is not clear whether the large financial cost of surveillance is justified.

In this critique, the authors asked whether surveillance works and answered with respect to identification of dysplasia using similar source material to that used as the basis for surveillance strategies.

This controversy emphasizes the lack of appropriate studies. These would require a regular, clearly defined surveillance protocol instituted in a randomly selected group of colitis patients meeting strict entry criteria, compared to a group of patients not undergoing surveillance colonoscopy. Definite criteria for surgical intervention must be instituted and followed, and complete follow-up would be required to detect any difference in mortality.

The difficulties of conducting such a protocol are clear because of the need to randomize patients to a control group, but lost containment concerns and the need to demonstrate clinical benefit require that such studies are undertaken.

Sheffield J, et al, Randomized, controlled trial of fecal occult blood screening for colorectal cancer. Lancet $1989 ; 1: 1160-4$.

14. Herz REL, Deddish MR, Day E. Value of periodic examinations in detecting cancer of the rectum and colon. Postgrad Med 1960;27:290-4.

15. Gilbertson VA. Proctosigmoidoscopy and polypectomy in reducing the incidence of rectal cancer. Cancer 1974;34:936-9.

16. Letsou G, Ballantyne GH, Zdon MJ, et al. Screening for colorectal neoplasms: Comparison of the fecal occult blood test and endoscopic examination. Dis Colon Rectum 1987;30:839-43.

17. Grossman S, Milos F. Colonoscopic screening of persons with suspected risk factors for colon cancer. Gastroenterology 1988;94:395-400.

18. Grossman S, Milos M, Teikawa I, et al. Colonoscopic screening of persons with suspected risk factors for colon cancer. II. Past history of colorectal 
neoplasms. Gastroenterology 1989;96:299-306

19. Guillem JG, Neugut AI, Forde KA, et al. Colonic neoplasms in asymptomatic first-degree relatives of colon cancer patients. Am J Gastroenterol 1988;83:271-3.

20. Love RR, Morrissey JF. Colonoscopy in asymptomatic individuals with a family history of colorectal cancer. Arch Intern Med 1984;144:2209-11.

21. Gryska PV, Cohen AM. Screening asymptomatic patients at high risk for colon cancer with full colonoscopy. Dis Colon Rectum 1987;30:18-20.

22. Mecklin JP, Jarvinen HJ, Aukee S, et al. Screening for colorectal carcinoma in cancer family syndrome kindreds. Scand J Gastroenterology 1987;22:449-53.

23. Rozen P, Fireman ZV, Figer A, et al. Colorectal tumor screening in women with a past history of breast, uterine, or ovarian malignancies. Cancer 1986;57:1235-9.

24. Barkin JS, Cohen ME, Flaxman M, et al. Value of a routine followup endoscopy program for the detection of recurrent colorectal carcinoma. Am J Gastroenterol 1988;12:1355-9.

25. Cochrane JPS, Williams JT, Faber RG, et al. Value of outpatient followup after curative surgery for carcinoma of the large bowel. $\mathrm{Br} \mathrm{Med} J$ 1980;280:128.

26. Weber CA, Deveney KE, Pelegrini $\mathrm{CA}$, et al. Routine colonoscopy in the management of colorectal carcinoma. Am J Surg 1986;152:87-92.

27. Ballantyne $\mathrm{GH}$, Modlin IM. Postoperative followup for colorectal cancer: Who are we kidding? J Clin Gastroenterol 1938;10:359-64. (Edit)

28. Olsen HW, Lawrence WA, Snook $\mathrm{CW}$, et al. Review of recurrent polyps and cancer in 500 patients with initial colonoscopy for polyps. Dis Colon Rectum 1988;31:222-7.

29. Dowling K, Watne AW, Foshag L, et al. Management of nonfamilial adenomatous polyps and colon cancers. Surgery 1985;98:684-8.

30. Morson B, Pan L. Rectal biopsy as an aid to cancer control in ulcerative colitis. Gut 1967;8:423-34.

31. Riddell R, Goldman H, Ransohoff DF, et al. Dysplasia inflammatory bowel disease. Standardized classification with provisional clinical applications. Hum Pathol 1983;14:931-68.

32. Blackstone MO, Riddell RH, Rogers BHG. Dysplasia associated lesion or mass (DALM) detected by colonoscopy in longstanding ulcerative colitis; An indication for colectomy. Gastroenterology 1981;80:366-74.

33. Riddell R, Morson B, Value of sigmoidoscopy and biopsy in detection of carcinoma and premalignant change in ulcerative colitis. Gut 1979;20:575-80.

34. Rosenstock E, Sivak M, Petras R, et al. Colonoscopic surveillance for dysplasia and cancer in chronic ulcerative colitis. Gastrointest Endosc 1984;30:145.

35. Rosenstock E, Farmer PG, Petras R, Sival MV Jr, Rankin GB. Surveillance for colonic carcinoma in ulcerative colitis. Gastroenterology 1985;89:1342-6.

36. Hunt RH, Teague RH, Swarbrick ET, Williams CB. Colonoscopy in the management of colonic strictures. Br Med J 1975;iii:360-1.

37. Brostrom $O$. The role of cancer surveillance in long term prognosis of ulcerative colitis. Scand J Gastroenterol 1983;18:40-2.

38. Brostrom O, Lofberg R, Reichard $\mathrm{H}$. Cancer surveillance of patients with longstanding ulcerative colitis: A clinical endoscopical and histological study. Gut 1986;27:1408-13.
39. Nugent FW, Haggitt HC. Results of a longterm prospective surveillance program for dysplasia in ulcerative colitis. Gastroenterology 1984;86:1197. (Abst)

40. Hanauer S, Riddell R, Levin B. Variability and significance of dysplastic findings in patients with chronic ulcerative colitis.

Gastroenterology 1983;84:1181.

41. Dickinson R, Dixon F, Axon A. Colonoscopy and the detection of dysplasia in patients with longstanding ulcerative colitis. Lancet 1980;ii:620-2.

42. Granqvist S, Gabrielsson N, Sundelin $\mathrm{P}$, et al. Precancerous lesions in the mucosa in ulcerative colitis. Scand ] Gastroenterol 1980;15:289-96.

43. Gabrielsson N, Granqvist S. Cancer surveillance by colonoscopy in total ulcerative colitis 1974-1984. Scand J Gastroenterol 1985;20:74.

44. Lennard-Jones JL, Morson B, Ritchie J, et al. Cancer in colitis: Assessment of the individual risk by clinical and histological criteria. Gastroenterology 1977;73:1280-9.

45. Fuson JA, Farmer RS, Hawk WA, Sullivan BH. Endoscopic surveillance for cancer in chronic ulcerative colitis. Am J Gastroenterol 1980;73:120-6.

46. Waye JD. Dysplasia and ulcerative colitis - A colonoscopic study. Scand J Gastroenterol 1983;18:44-7.

47. Lennard-Jones JL, Ritchie J, Morson B, et al. Cancer surveillance in ulcerative colitis. Lancet 1983; ii:149-52.

48. Hunt RH, Riddell RH. Cancer surveillance in ulcerative colitis. In: Ireland A, Jewell D, eds. Topics in Gastroenterology. Oxford: Blackwell Scientific, 1988:117-85.

49. Collins RH, Feldman M, Fordtran JS. Colon cancer, dysplasia, and surveillance in patients with ulcerative colitis. N Engl J Med 1987;316:1654-8. 


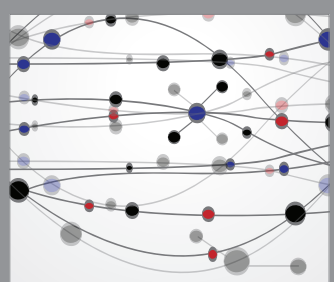

The Scientific World Journal
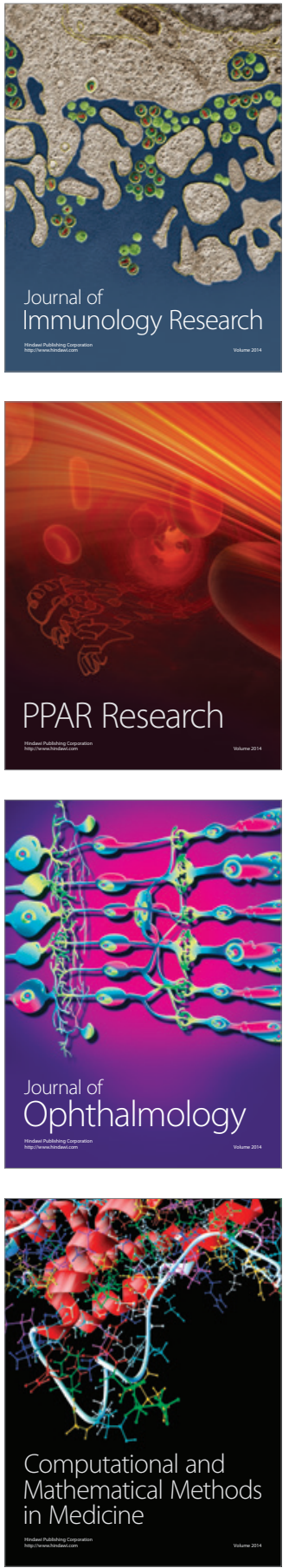

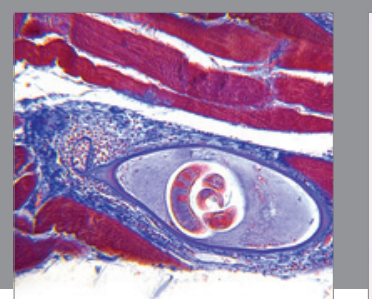

Gastroenterology Research and Practice

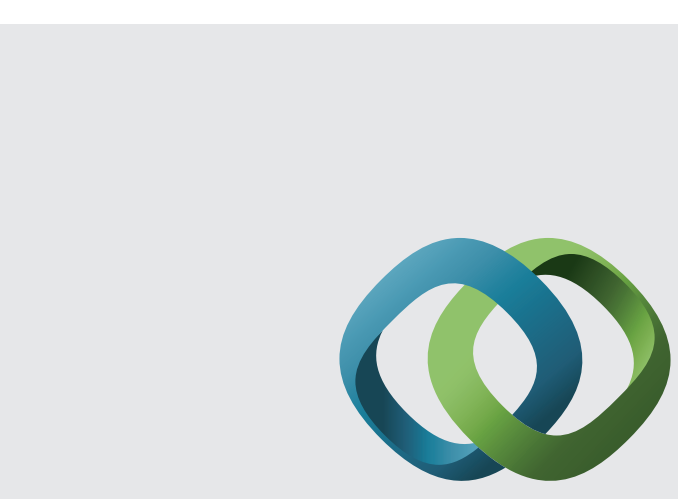

\section{Hindawi}

Submit your manuscripts at

http://www.hindawi.com
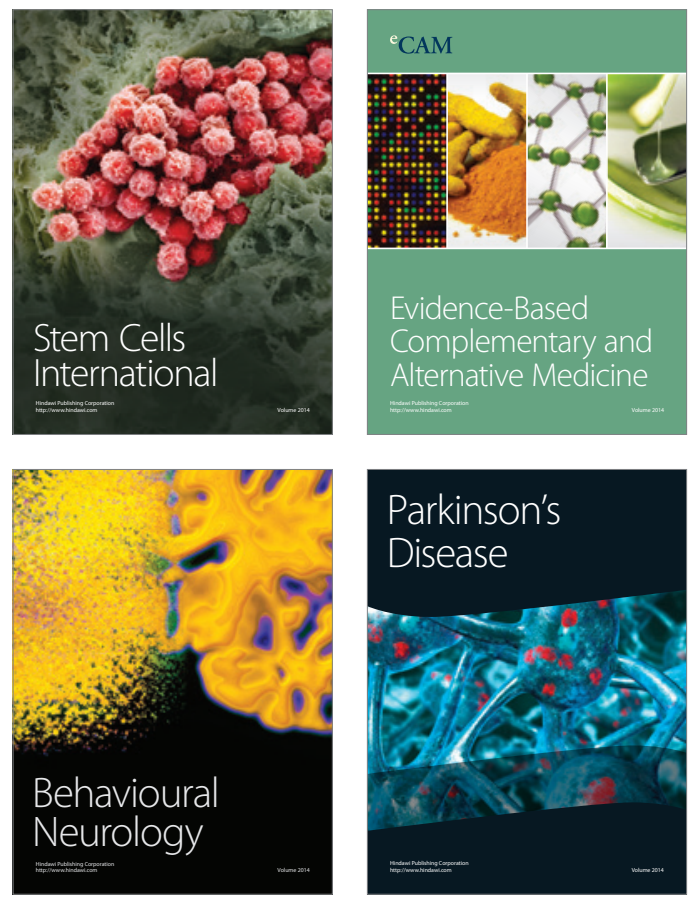
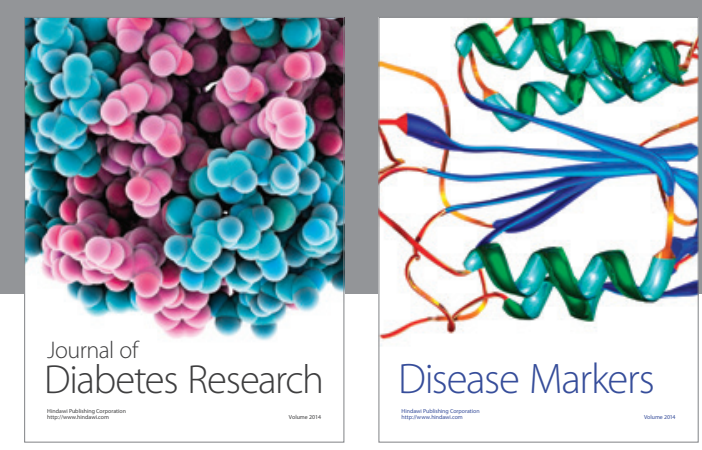

Disease Markers
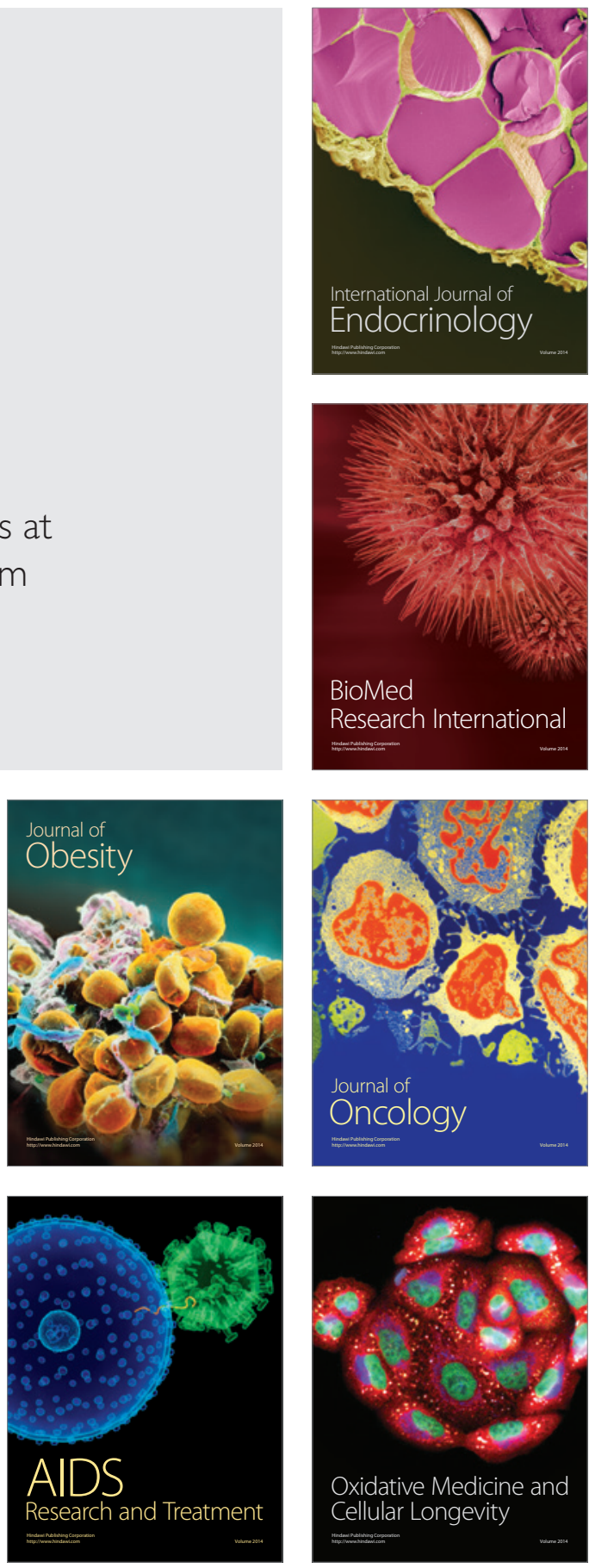